\title{
Central Nervous System Embryonal Tumor with Rhabdoid Features
}

National Cancer Institute

\section{Source}

National Cancer Institute. Central Nervous System Embryonal Tumor with Rhabdoid

Features. NCl Thesaurus. Code C129501.

A central nervous system embryonal neoplasm characterized by the presence of histological features consistent with atypical teratoid/rhabdoid tumor and absence of mutations of the INI1 gene or SMARCA4 (BRG1) gene. 